ARTICLE

Received 20 May 2014 | Accepted 29 Oct 2014 | Published 16 Dec $2014 \quad$ DOl: 10.1038/ncomms6693

\title{
Effectively suppressing dissolution of manganese from spinel lithium manganate via a nanoscale surface-doping approach
}

Jun $\mathrm{Lu}^{1, \star}$, Chun Zhan ${ }^{1,2, \star}$, Tianpin $\mathrm{Wu}^{3}$, Jianguo $\mathrm{Wen}^{4}, \mathrm{Yu} \mathrm{Lei}^{5}, \mathrm{~A}$. Jeremy Kropf ${ }^{1}$, Huiming Wu${ }^{1}$, Dean J. Miller ${ }^{4}$, Jeffrey W. Elam ${ }^{6}$, Yang-Kook Sun ${ }^{7}$, Xinping Qiu $^{2} \&$ Khalil Amine ${ }^{1}$

The capacity fade of lithium manganate-based cells is associated with the dissolution of $\mathrm{Mn}$ from cathode/electrolyte interface due to the disproportionation reaction of $\mathrm{Mn}(\mathrm{III})$, and the subsequent deposition of $\mathrm{Mn}$ (II) on the anode. Suppressing the dissolution of $\mathrm{Mn}$ from the cathode is critical to reducing capacity fade of $\mathrm{LiMn}_{2} \mathrm{O}_{4}$-based cells. Here we report a nanoscale surface-doping approach that minimizes $\mathrm{Mn}$ dissolution from lithium manganate. This approach exploits advantages of both bulk doping and surface-coating methods by stabilizing surface crystal structure of lithium manganate through cationic doping while maintaining bulk lithium manganate structure, and protecting bulk lithium manganate from electrolyte corrosion while maintaining ion and charge transport channels on the surface through the electrochemically active doping layer. Consequently, the surface-doped lithium manganate demonstrates enhanced electrochemical performance. This study provides encouraging evidence that surface doping could be a promising alternative to improve the cycling performance of lithium-ion batteries.

\footnotetext{
${ }^{1}$ Division of Chemical Sciences and Engineering, Argonne National Laboratory, Argonne, Illinois 60439, USA. ${ }^{2}$ Department of Chemistry, Key Laboratory of Organic Optoelectronics and Molecular Engineering, Tsinghua University, Beijing 100084, China. ${ }^{3}$ Division of X-ray Science, Argonne National Laboratory, Argonne, Illinois 60439, USA. ${ }^{4}$ Electron Microscopy Center, Argonne National Laboratory, Argonne, Illinois 60439, USA. ${ }^{5}$ Department of Chemical and Materials Engineering, University of Alabama in Huntsville, Huntsville, Alabama 35899, USA. ${ }^{6}$ Division of Energy Systems, Argonne National Laboratory, Argonne, Illinois 60439, USA. ${ }^{7}$ Department of Energy Engineering, Hanyang University, Seoul 133-791, South Korea. * These authors contributed equally to this work. Correspondence and requests for materials should be addressed to J.L. (email: junlu@anl.gov) or to X.Q. (email: qiuxp@mail.tsinghua.edu.cn) or to K.A. (email: amine@anl.gov).
} 
$\mathrm{O}$ wing to their high energy density, lithium-ion batteries (LIBs) are recognized as one of the most appropriate and promising energy-storage systems and are being pursued intensively for transportation applications, including hybrid electric vehicles, plug-in hybrid electric vehicles and pure electric vehicles (PEVs). However, current LIBs do not meet many of the performance and safety requirements for use in PEVs and, therefore, improvements in cell chemistry are being actively pursued to develop a safe and reliable high-performance battery.

The cathode is generally regarded as the capacity-determining component of a LIB. Ideally, the cathode should deliver high specific capacity, high operating voltage, low cost, superior safety and long cycle life within a wide working temperature range in order to meet the requirements for PEV applications ${ }^{1,2} . \mathrm{LiMn}_{2} \mathrm{O}_{4}$ with the spinel structure, which shows a reversible $\mathrm{Li}$ (de)intercalation plateau at $\sim 4.0 \mathrm{~V}$ versus $\mathrm{Li}_{/} / \mathrm{Li}^{+}$, is one of the most promising cathode materials to meet the above requirements. However, the poor cycling performance of this material, particularly at elevated temperatures, limits its wide application as a cathode material for LIBs ${ }^{3}$. Previous studies ${ }^{4-11}$ demonstrated that the capacity fade of $4 \mathrm{~V} \mathrm{LiMn}{ }_{2} \mathrm{O}_{4}$ cells is directly associated with the dissolution of $\mathrm{Mn}$ from the cathode/ electrolyte interface because of the disproportionation reaction of $\mathrm{Mn}(\mathrm{III})$, and the subsequent deposition of $\mathrm{Mn}^{2+}$ on the anode, thereby increasing the cell impedance. Consequently, suppressing $\mathrm{Mn}$ dissolution from the cathode is critical to overcoming capacity fade of the $\mathrm{LiMn}_{2} \mathrm{O}_{4}$ cell.

One approach to limit the dissolution of $\mathrm{Mn}$ from $\mathrm{LiMn}_{2} \mathrm{O}_{4}$ is cationic doping on the bulk level, which helps to stabilize the $\mathrm{LiMn}_{2} \mathrm{O}_{4}$ crystal structure. The substitution of $\mathrm{Mn}$ by cations, such as $\mathrm{Al}^{3+}$ or $\mathrm{Ti}^{4+}$, has been successfully used to minimize capacity fade, but with an inevitable sacrifice of the specific capacity due to the electrochemical inactivity of these dopant ions ${ }^{12-16}$. Both cycling performance and capacity can be improved if an electrochemically active cation, for instance, $\mathrm{Ni}^{2}+$ or $\mathrm{Co}^{2+}$, is applied as the dopant. However, such doped $\mathrm{LiMn}_{2} \mathrm{O}_{4}$ could lead to safety issues because of the high chemical activity of the doped cations, in particular, $\mathrm{Ni}^{4+}$ (refs 17-19).

Another approach that has been widely used to suppress $\mathrm{Mn}$ dissolution from $\mathrm{LiMn}_{2} \mathrm{O}_{4}$ is to coat the surface, thereby preventing direct contact between the electrolyte and $\mathrm{LiMn}_{2} \mathrm{O}_{4}$.

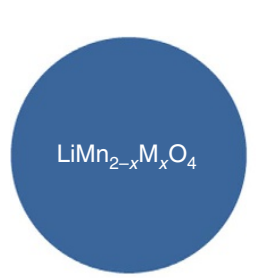

Bulk-doping structure

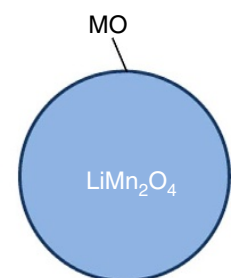

Surface-coating structure

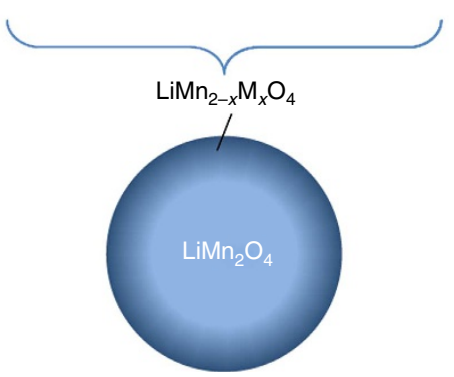

Surface-doping structure

Figure 1 | Schematic illustration. The structures resulting from bulkdoping, surface-coating and surface-doping ( $M$ represents the dopant cation).
For instance, thin metal oxide coatings on the spinel surface can enhance the resistance of $\mathrm{LiMn}_{2} \mathrm{O}_{4}$ against hydrogen fluoride attack from the electrolytes ${ }^{20-22}$, which is the primary mechanism for $\mathrm{Mn}$ dissolution. However, uniformity and continuity of the coating layers remain an issue since uncoated portions of the active materials are still subject to electrochemical attack. In some cases, surface-coating does not significantly reduce capacity fade. Another issue with the surface-coating approach is the potential dissimilarity of crystal structures between the coating layer and the active $\mathrm{LiMn}_{2} \mathrm{O}_{4}$ spinel material. The heterostructural interface between the coating layer and the active material may lead to phase segregation or separation during cycling of the cell. In addition, the higher resistance imposed by some surface coatings can block ionic and electronic transportation channels on the $\mathrm{LiMn}_{2} \mathrm{O}_{4}$ surface ${ }^{20}$, leading to a significant decrease in the cell capacity.

In light of the above issues, the present study explores an alternative approach to suppress $\mathrm{Mn}$ dissolution from $\mathrm{LiMn}_{2} \mathrm{O}_{4}$ and thereby improve the cycling performance of the cell, especially at elevated operating temperature. We propose a nanoscale surface-doping approach to exploit the advantages of both bulk doping and surface-coating techniques while maintaining high capacity, safety, charge transport and cathode stability. In our approach, an electrochemically inactive cation, in this case $\mathrm{Ti}^{4+}$, is incorporated only into the surface (a few nanometres thick only) of the spinel $\mathrm{LiMn}_{2} \mathrm{O}_{4}$ to form a cationdoped $\mathrm{LiMn}_{2-x} \mathrm{Ti}_{x} \mathrm{O}_{4}$ surface layer, as illustrated in Fig. 1. This approach exploits the advantage of bulk doping, that is, stabilization of the $\mathrm{LiMn}_{2} \mathrm{O}_{4}$ crystal structure throughout the particle. At the same time, the cation-doped surface layer protects the bulk $\mathrm{LiMn}_{2} \mathrm{O}_{4}$ from acid corrosion like a surface-coating layer. However, unlike the physical barrier imposed by surface coatings, the $\mathrm{LiMn}_{2-x} \mathrm{Ti}_{x} \mathrm{O}_{4}$ surface layer is electrochemically active and therefore maintains the ion and charge transport channels on the surface. Moreover, the sol-gel method used in this study provides a uniform surface-doped layer over the entire particle and minimizes possible phase segregation owing to the structural similarity between the surface-doped layer $\left(\mathrm{LiMn}_{2-x} \mathrm{Ti}_{x} \mathrm{O}_{4}\right)$ and spinel $\mathrm{LiMn}_{2} \mathrm{O}_{4}$. As a consequence, the surface-doped $\mathrm{LiMn}_{2} \mathrm{O}_{4}$ demonstrates significantly enhanced electrochemical performance in terms of cycleability and capacity at elevated temperature. This study suggests that surface doping is a promising alternative approach to improve the cycle performance of the LIBs.

\section{Results}

Characterization of the surface-doping and -coating structures. To evaluate our surface-doping approach, two surface modification methods were utilized on pre-synthesized $\mathrm{LiMn}_{2} \mathrm{O}_{4}$, as detailed in the experimental section. In one method, a $\mathrm{TiO}_{2}$-surface-doped $\mathrm{LiMn}_{2} \mathrm{O}_{4}$ (designated as TSD-LMO hereafter) was prepared using sol-gel technique. In the other approach, $\mathrm{TiO}_{2}$-surface-coated $\mathrm{LiMn}_{2} \mathrm{O}_{4}$ (designated as TSCLMO hereafter) was prepared using atomic layer deposition $(\mathrm{ALD})^{23}$. The starting material in both cases consisted of $\mathrm{LiMn}_{2} \mathrm{O}_{4}$ particles with a particle size $\sim 200 \mathrm{~nm}$ prepared by a conventional solid-state method (Fig. 2a). The smooth facets, particle size and octahedral morphology of the unmodified $\mathrm{LiMn}_{2} \mathrm{O}_{4}$ particles were unchanged after both the surface-doping (Fig. 2b), and ALD-coating (Fig. 2c).

The crystal structures of the samples were characterized by high-energy X-ray diffraction (XRD) as shown in Fig. 3. The XRD patterns for all three samples exhibit only the characteristic diffraction peaks for a well-crystallized spinel structure with Fd-3m symmetry. Rietveld refinements of these XRD showed that 

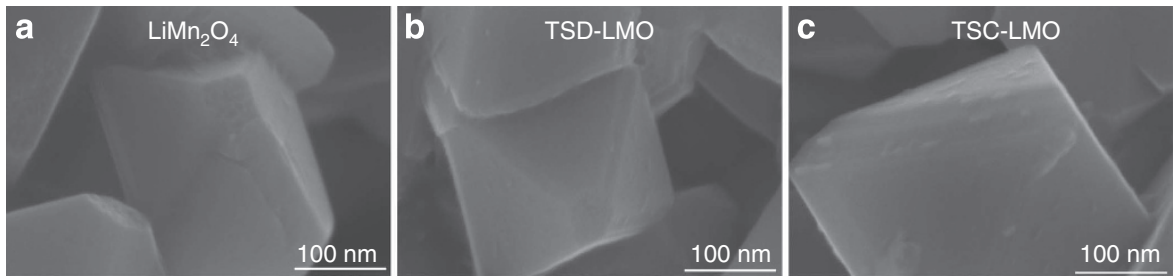

Figure 2 | Scanning electron microscopy images of particles. (a) Unmodified $\mathrm{LiMn}_{2} \mathrm{O}_{4}$, (b) TSD-LMO via sol-gel method and (c) TSC-LMO via ALD (scale bar in all images, $100 \mathrm{~nm}$ ).

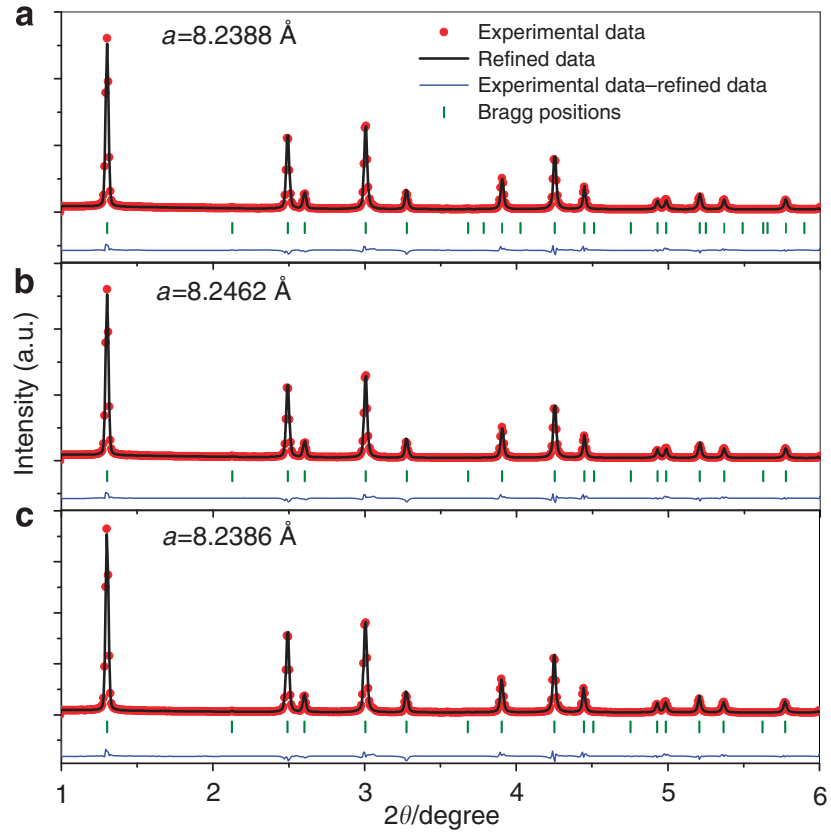

Figure 3 | XRD patterns and corresponding cubic lattice parameters.

(a) Unmodified $\mathrm{LiMn}_{2} \mathrm{O}_{4}$, (b) TSD-LMO via sol-gel method and

(c) TSC-LMO via ALD. The red dots, black lines, blue lines and green bars represent the experimental data, refined data, their difference and the Bragg positions, respectively.

the TSC-LMO sample has essentially the same lattice parameter as that of the unmodified $\mathrm{LiMn}_{2} \mathrm{O}_{4}$, indicating that the ALD surface-coating does not change the crystal structure of $\mathrm{LiMn}_{2} \mathrm{O}_{4}$, either on the surface or within the bulk. However, in the case of the TSD-LMO sample the lattice parameter is slightly increased compared with the as-synthesized powder. This increase in lattice parameter can be attributed to the diffusion of $\mathrm{Ti}^{4+}$ ions into the surface spinel lattice by replacing some of the manganese ions of $\mathrm{LiMn}_{2} \mathrm{O}_{4}$ during the sol-gel process. The resulting surface-doped $\mathrm{LiMn}_{2-} \mathrm{Ti}_{x} \mathrm{O}_{4}$ spinel-type layer has a slightly higher lattice parameter because the ionic radius of $\mathrm{Ti}^{4+}$ is larger than that of the manganese ion ${ }^{24-27}$. In addition, the absence of $\mathrm{TiO}_{2}$ peaks in the XRD patterns for the TSC-LMO sample is probably caused by the low concentration or the amorphous state of the ALD $\mathrm{TiO}_{2}$.

X-ray absorption spectroscopy (XAS) measurements were performed to evaluate the local bonding environment for the $\mathrm{Ti}$ and $\mathrm{Mn}$ ions in both samples. Figure 4a,b shows Mn K-edge XAS spectra for TSC-LMO and TSD-LMO samples. Both surfacemodified $\mathrm{LiMn}_{2} \mathrm{O}_{4}$ samples exhibit nearly identical features as the unmodified $\mathrm{LiMn}_{2} \mathrm{O}_{4}$ in X-ray absorption near edge structure (XANES, Fig. 4a) and in extended X-ray absorption fine structure (Fig. 4b) spectra. These results suggest that the bulk crystal structure of spinel $\mathrm{LiMn}_{2} \mathrm{O}_{4}$ is not affected by the surface modifications. The Ti K-edge EXAFS spectra in Fig. 4d, on the other hand, reveal a significant difference of the bonding length of the Ti species on the surface between the TSC-LMO and TSDLMO samples, although the Ti K-edge XANES data (Fig. 4c) showed that $\mathrm{Ti}$ is tetravalent in both samples. The Fourier transform for the first shell coordination of the TSC-LMO sample (black curve in Fig. 4d) has two main peaks: a large peak at $\sim 1.4 \AA$ (uncorrected distance for Ti-O) and a smaller peak at $\sim 2.4 \AA$ (uncorrected distance for Ti-Ti). This spectrum is typical for the K-edge extended X-ray absorption fine structure of $\mathrm{TiO}_{2}$. The TSD-LMO sample also shows typical $\mathrm{Ti}-\mathrm{O}$ and $\mathrm{Ti}-\mathrm{Ti}$ bonding features (red curve in Fig. 4d); however, two extra bonding features are also observed (marked as arrow), likely because of either the interactions between $\mathrm{Ti}$ and $\mathrm{Mn}(\mathrm{IV} / \mathrm{III})$ (that is, $\mathrm{Ti}-\mathrm{Mn}^{4+}$ and $\mathrm{Ti}-\mathrm{Mn}^{3+}$ ) or $\mathrm{Ti}-\mathrm{O}$ bonding with different bond length in the TSD-LMO sample. This can be attributed to the diffusion of $\mathrm{Ti}^{4+}$ into the surface of the $\mathrm{LiMn}_{2} \mathrm{O}_{4}$ particles and the formation of a surface-doped $\mathrm{LiMn}_{2-x} \mathrm{Ti}_{x} \mathrm{O}_{4}$ layer during the calcination process. The XAS results provide further evidence that the TSD-LMO sample has a different surface crystal structure from that of the TSC-LMO sample.

Next, the surface compositions of the samples were examined by X-ray photoelectron spectroscopy (XPS), as shown in Fig. 5 . Ti $2 \mathrm{p}_{1 / 2}$ and $2 \mathrm{p}_{3 / 2}$ peaks at about 463.8 and $458.2 \mathrm{eV}$ with a spinorbit splitting of $5.60 \mathrm{eV}$ can be assigned to Ti(IV) (Fig. 5a), illustrating the formation of $\mathrm{Ti}^{4+}$-containing layers for both the TSC-LMO and TSD-LMO samples, in agreement with the Ti K-edge XANES results. A more distinct difference between the TSC-LMO and TSD-LMO samples can be observed in the Mn 2p spectra shown in Fig. 5b. The TSC-LMO sample exhibits a Mn 2p spectrum similar to the unmodified $\mathrm{LiMn}_{2} \mathrm{O}_{4}$, with the molar ratio of $\mathrm{Mn}^{3+}: \mathrm{Mn}^{4+}$ of 1:1. However, in the case of the TSDLMO sample, the Mn $2 p$ peaks moves toward higher binding energy (by about $0.4 \mathrm{eV}$ ), and the molar ratio of $\mathrm{Mn}^{3+}: \mathrm{Mn}^{4+}$ is 2:1. This indicates that some of the $\mathrm{Mn}^{4+}$ cations on the surface of the spinel $\mathrm{LiMn}_{2} \mathrm{O}_{4}$ particles have been replaced by $\mathrm{Ti}^{4+}$ in the TSD-LMO sample, supporting the conclusion that the TSD-LMO sample has a different surface composition compared to the TSC-LMO sample.

High-resolution transmission electron microscopy (HR-TEM) was used to further investigate the surface morphology and crystallinity of the samples. Figure 6a presents the HR-TEM image for the unmodified $\mathrm{LiMn}_{2} \mathrm{O}_{4}$, showing that the particles are well crystallized with lattice spacing of $4.8 \AA$, corresponding to the (1-11) spacing of bulk $\mathrm{LiMn}_{2} \mathrm{O}_{4}$ and have an atomically smooth surface. After the surface-doping via sol-gel method, the TSDLMO sample retains the atomically smooth surface and spinel structure, as illustrated in Fig. 6b,c. The presence of Ti in the TSD-LMO surface is confirmed by the electron energy loss spectroscopy (EELS) spectra on different spots of a selected particle (Fig. 6d,e). These results indicate that $\mathrm{Ti}^{4+}$ from the solgel precursor diffuses into the $\mathrm{LiMn}_{2} \mathrm{O}_{4}$ particle to form a doped layer $\left(\mathrm{LiMn}_{2}{ }_{-x} \mathrm{Ti}_{x} \mathrm{O}_{4}\right)$ on the particle surface during the sol-gel process. Figure $6 \mathrm{f}$ shows the HR-TEM image for the TSC-LMO 

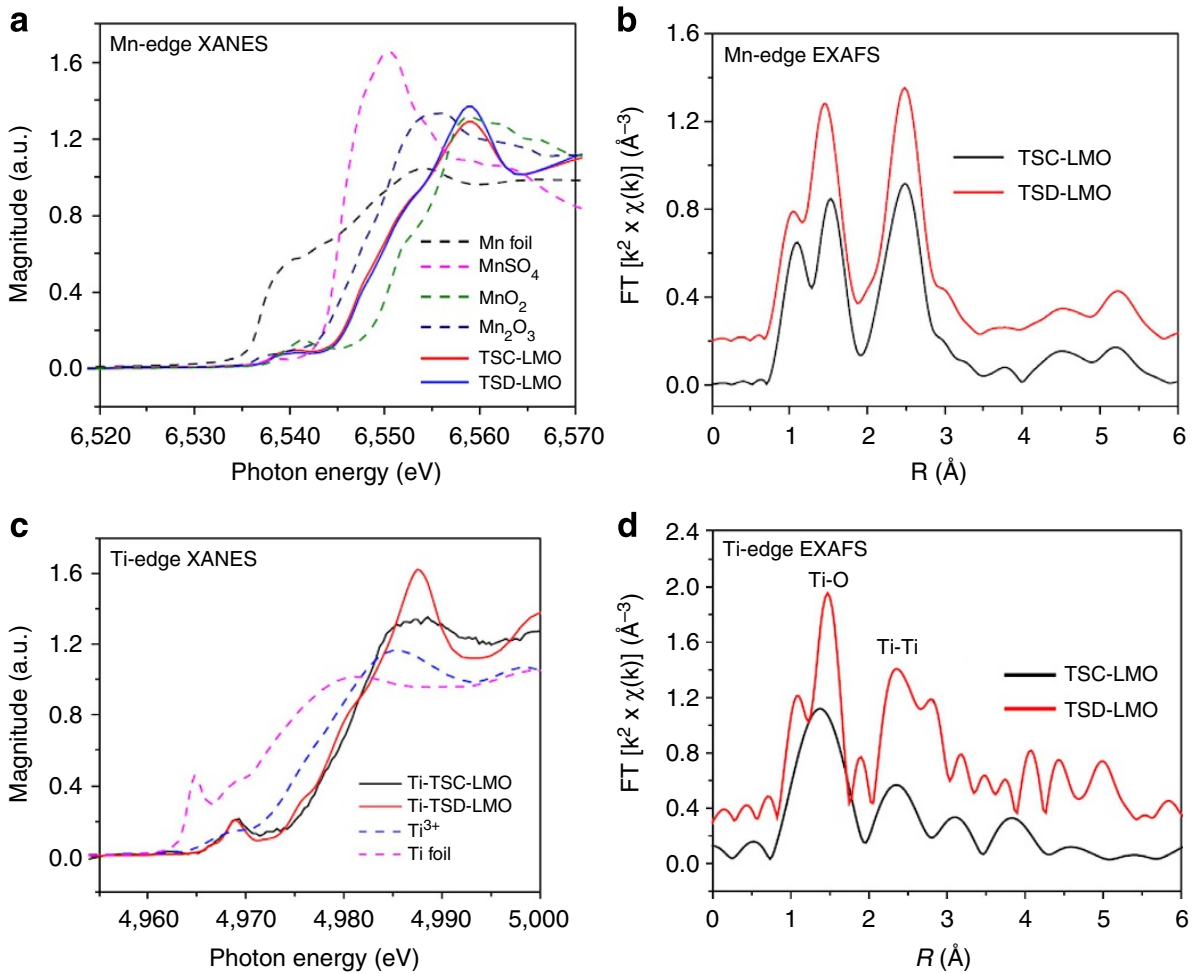

Figure 4 | X-ray absorption spectroscopy. (a) Mn K-edge XANES, (b) Mn K-edge EXAFS, (c) Ti K-edge XANES, (d) Ti K-edge EXAFS spectra for $\operatorname{TSC}$-LMO $\left(k=2-7.5 \AA^{-1}\right)$ and TSD-LMO $\left(k=1.7-12 \AA^{-1}\right)$ samples.
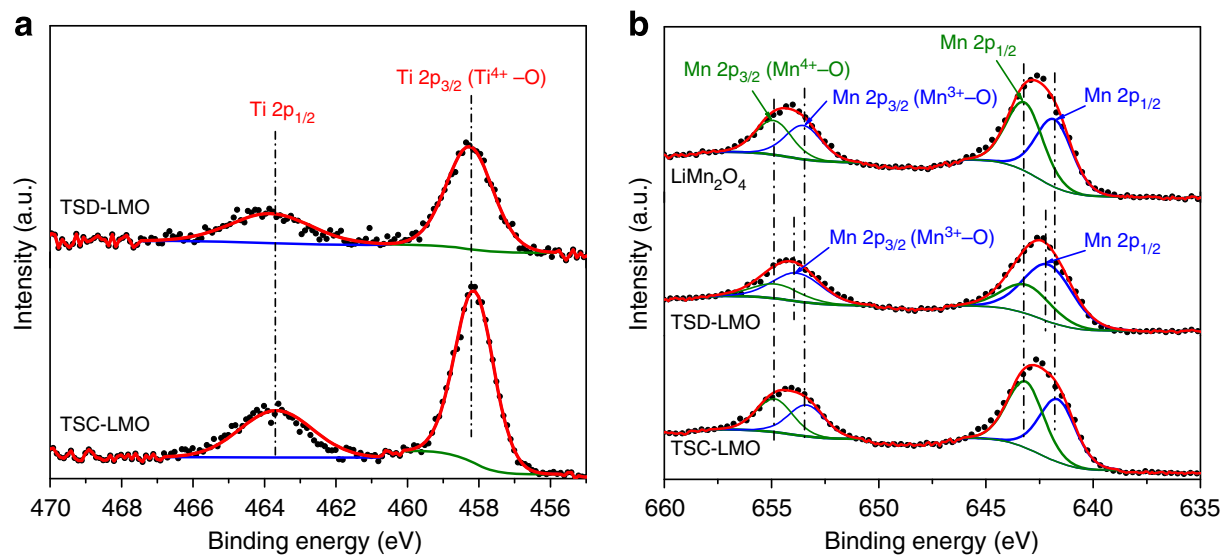

Figure 5 | X-ray photoelectron spectroscopy. (a) Ti $2 \mathrm{p}$ and (b) Mn $2 \mathrm{p}$ spectra of unmodified $\mathrm{LiMn}_{2} \mathrm{O}_{4}$, TSD-LMO via sol-gel method and TSC-LMO via ALD. The dots and lines represent the experimental data and fitted data, respectively.

sample, and reveals island-like particles attached to the surface of the $\mathrm{LiMn}_{2} \mathrm{O}_{4}$ particles after the ALD coating. These island-like particles have a lattice spacing close to $1.5 \AA$, consistent with $\mathrm{TiO}_{2}$. The HR-TEM (Fig. 6f) and EELS from different spots (A and B in Fig. $6 \mathrm{~g}$ ) of a selected TSC-LMO particle confirm that the ALD $\mathrm{TiO}_{2}$ exists as a physically distinct phase attached to the $\mathrm{LiMn}_{2} \mathrm{O}_{4}$ surface, which is a completely different surface structure from the TSD-LMO sample.

The comprehensive characterization described above demonstrates that the sol-gel and ALD approaches for modifying the $\mathrm{LiMn}_{2} \mathrm{O}_{4}$ surface yield distinctly different outcomes. In particular, the sol-gel approach generates a continuous surface region enhanced in the electrochemically inactive, and dissolutionresistant $\mathrm{Ti}^{4+}$, but without disturbing the spinel crystalline structure that gives rise to high ionic and electronic conductivity. Consequently, this should be beneficial to electrochemical performance in terms of cycleability and capacity, as demonstrated below.

Improvement in the electrochemical stability of the spinel cathode. The charge/discharge behaviours of the unmodified and surfaced-modified $\mathrm{LiMn}_{2} \mathrm{O}_{4}$ electrodes cycled between 3.5 and $4.3 \mathrm{~V}$ at $55^{\circ} \mathrm{C}$ are compared in Fig. 7. As shown in Fig. 7a, two plateaus are observed in the charge or discharge curves for all three samples, which can be readily assigned to a one-phase transition reaction at $3.9 \mathrm{~V}$ and a two-phase transition reaction at $4.1 \mathrm{~V}$, respectively ${ }^{28}$. Despite differences in the capacities, the unmodified and TSC-LMO electrode exhibited similar charge/ discharge curves in shape, while the plateaus for the TSD-LMO electrode were rather different. These differences in the plateau shape can be seen more clearly in the differential capacity versus 

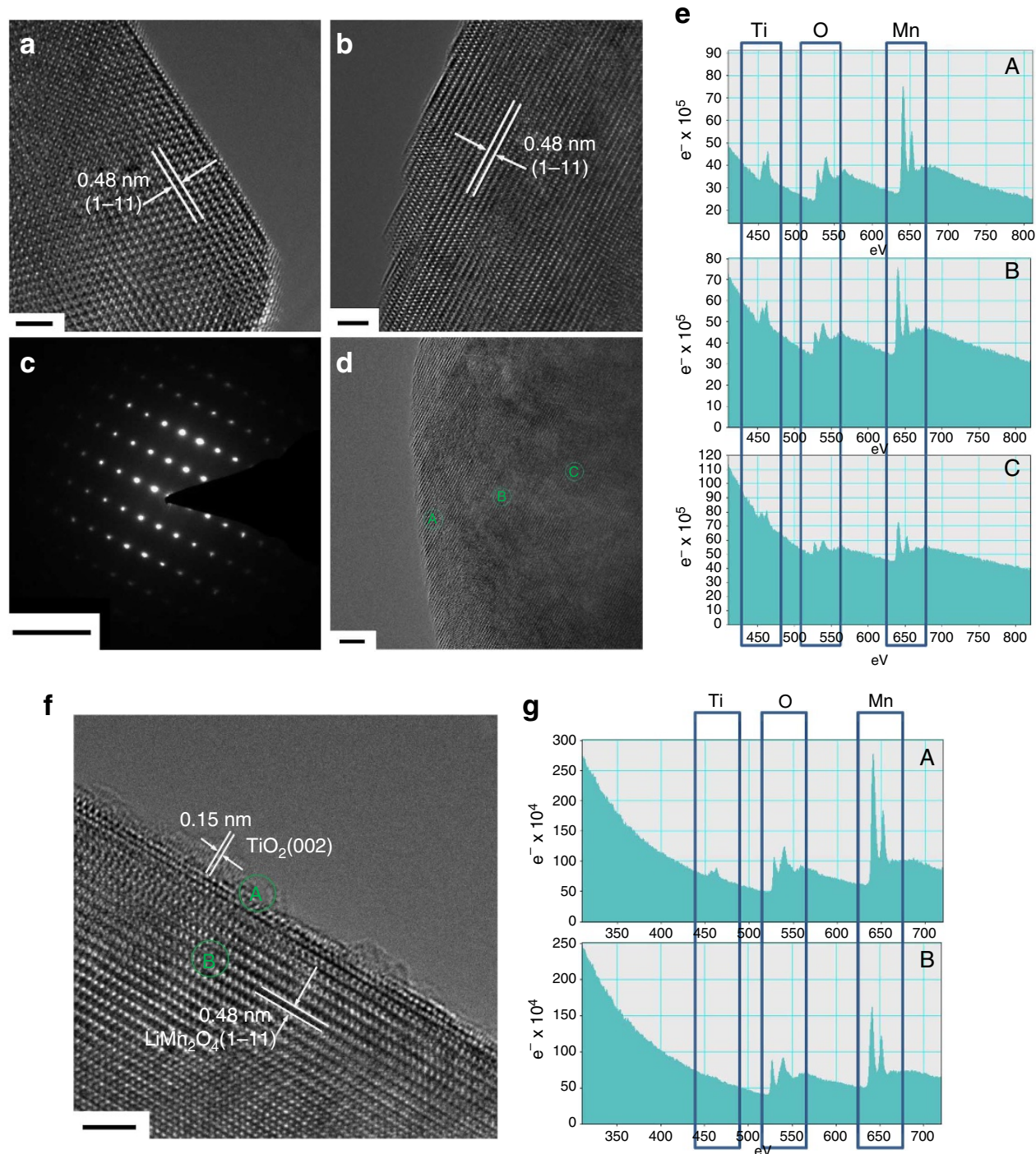

Figure 6 | High-resolution TEM images of surface-treated $\mathbf{L i M n}_{\mathbf{2}} \mathbf{O}_{\mathbf{4}}$ particles. (a,b) High-resolution TEM images of surface-doped LiMn $\mathrm{O}_{4}$ particles showing uniform structure from surface to the interior (scale bar, $2 \mathrm{~nm}$ ). (c) Selected area diffraction pattern along [112] for the region shown in $\mathbf{b}$. (d) TEM image with regions indicated for the corresponding EELS data shown in e (scale bar, $5 \mathrm{~nm}$ ). (f) High-resolution TEM image of surface-coated $\mathrm{LiMn}_{2} \mathrm{O}_{4}$ particle (scale bar, $5 \mathrm{~nm}$ ). (g) EELS spectra from regions $\mathrm{A}$ and $\mathrm{B}$ in (f).
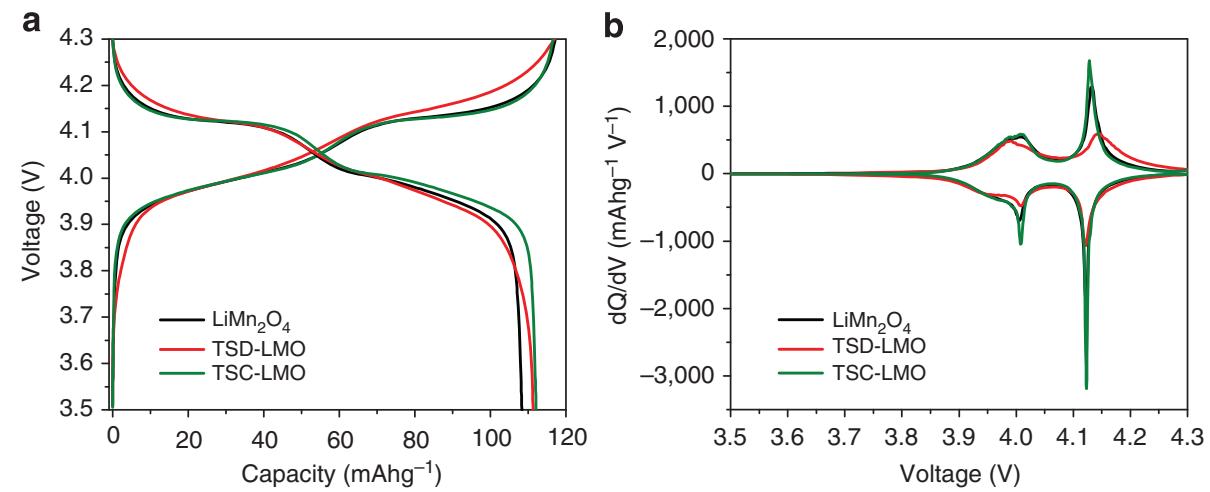

Figure 7 | The cycle-discharge behaviour analysis. (a) Charge-discharge profile and (b) differential capacity versus voltage curves of the first cycle of the cells with surface-treated and -unmodified $\mathrm{LiMn}_{2} \mathrm{O}_{4}$ electrodes cycled between 3.5 and $4.3 \mathrm{~V}$ at $\mathrm{C} / 10$ and $55^{\circ} \mathrm{C}$.

voltage $(\mathrm{d} Q / \mathrm{d} V$ versus $V)$ curves, as shown in Fig. $7 \mathrm{~b}$. The oxidation peak at $\sim 4.1 \mathrm{~V}$ was significantly broadened in the TSD-LMO electrode, which is likely because of the formation of a $\mathrm{LiMn}_{2-x} \mathrm{Ti}_{x} \mathrm{O}_{4}$ layer on the surface of the $\mathrm{LiMn}_{2} \mathrm{O}_{4}$ particles.
This layer can subsequently influence the phase transition process because of the change in the crystal structure of the surface. In addition, the initial columbic efficiencies of the TSD-LMO and TSC-LMO (94.9\% and 96.1\%, respectively) are higher than that of 


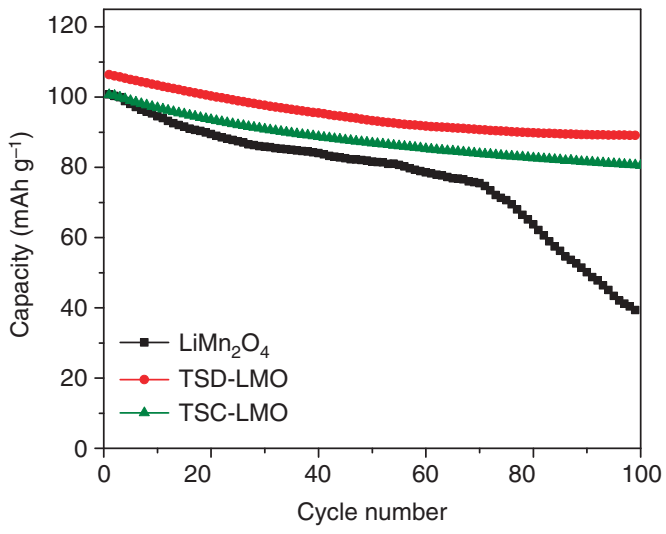

Figure 8 | Cycling performance. Cycling performance for unmodified $\mathrm{LiMn}_{2} \mathrm{O}_{4}$, TSD-LMO via sol-gel deposition and TSC-LMO via ALD, at the rate of $\mathrm{C} / 2$ and $55^{\circ} \mathrm{C}$.

the unmodified LMO (92.3\%), indicating that in both cases the surface modification can suppress irreversible reactions (such as deposition of electrolyte decomposition products) on the surface of the cathodes, owing to the stabilized surface structure.

The cycling performance of the surface-modified $\mathrm{LiMn}_{2} \mathrm{O}_{4}$ samples at elevated temperature $\left(55^{\circ} \mathrm{C}\right)$ is shown in Fig. 8. Both the TSD-LMO and TSC-LMO samples showed considerably improved cycle performance compared with the unmodified $\mathrm{LiMn}_{2} \mathrm{O}_{4}$. Capacity fade was clearly observed for the unmodified $\mathrm{LiMn}_{2} \mathrm{O}_{4}$ cell after 20 cycles and this fade severely accelerated after 70 cycles. By the end of the 100th cycle, the unmodified $\mathrm{LiMn}_{2} \mathrm{O}_{4}$ cell had lost almost $60 \%$ of its initial capacity. In contrast, the capacity loss of the surface-modified $\mathrm{LiMn}_{2} \mathrm{O}_{4}$ (TSD-LMO and TSC-LMO) cells is much lower, indicating that surface modification effectively stabilizes the crystal structure of $\mathrm{LiMn}_{2} \mathrm{O}_{4}$ and minimizes $\mathrm{Mn}$ dissolution. Moreover, the TSD-LMO electrode shows a higher specific capacity than the TSC-LMO electrode in the same voltage window. This is most likely due to faster Li-ion transfer through the Ti-doped $\left(\mathrm{LiMn}_{2-x} \mathrm{Ti}_{x} \mathrm{O}_{4}\right)$ layer of the TSD-LMO sample compared with transport through the $\mathrm{TiO}_{2}$-coating layer of the TSC-LMO samples. To confirm this, we performed electrochemical impedance spectroscopy on the samples after the charge-discharge cycle test.

Figure 9 shows the AC impedance spectra (Nyquist plots) of the unmodified and surface-modified $\mathrm{LiMn}_{2} \mathrm{O}_{4}$ electrodes measured at $50 \%$ depth of discharge (DOD) during the first discharge and after cycling at $55^{\circ} \mathrm{C}$. The equivalent circuit shown in the insert of Fig. 8 was used to fit the spectra, where $R_{\mathrm{s}}$ is the electrolyte resistance, and $R_{\mathrm{SEI}}$ and $C_{\mathrm{SEI}}$ are the resistance and geometric capacitance of the anode solid-electrolyte interphase, respectively. $R_{\mathrm{ct}}$ reflects the charge-transfer resistance, $C_{\mathrm{dl}}$ represents the double-layer capacitance that takes the roughness of the particle surface into account, and $Z_{\mathrm{W}}$ is the Warburg diffusional impedance. The semicircle at the high-frequency region of the impedance spectra can be assigned to the $R_{\mathrm{SEI}} C_{\mathrm{SEI}}$ and $R_{\mathrm{ct}} C_{\mathrm{dl}}$ elements, while the slope of the low-frequency region is governed by the Warburg diffusion of Li ions from the surface to the centre of the cathode particles ${ }^{29,30}$. As shown in Fig. 9a and listed in Table $1, R_{\mathrm{ct}}$ of the LMO electrode was increased by the surface modification because the surface-doping and -coating layers are not as favourable for $\mathrm{Li}$ ion intercalation as the unmodified spinel. However, it is worth noting that $R_{\mathrm{ct}}$ for the TSD-LMO electrode $(55.3 \Omega)$ is much smaller than that for the TSC-LMO electrode $(95.8 \Omega)$, indicating that charge transfer on the surface of the TSD-LMO is faster than that of TSC-LMO. This

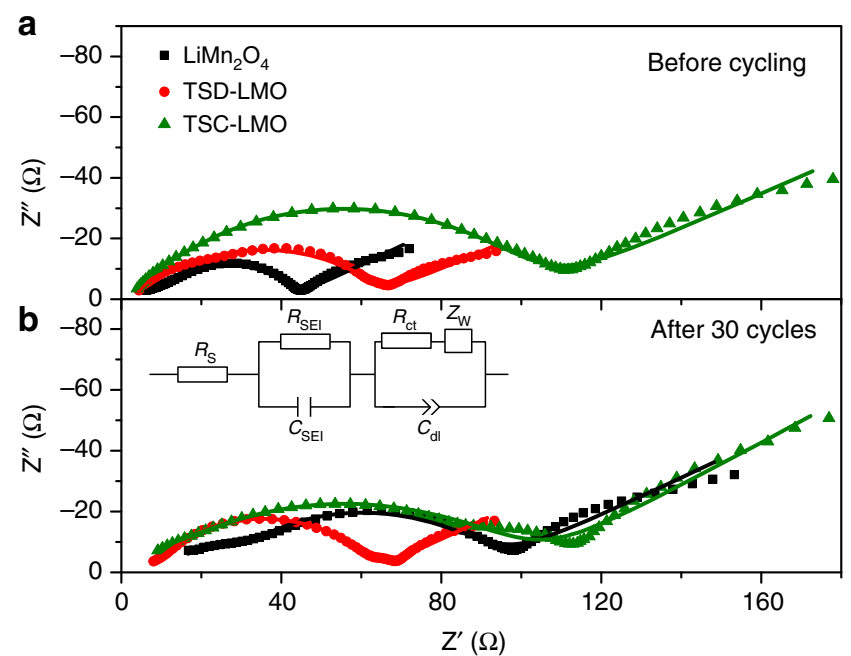

Figure 9 | Impedance spectra. Impedance spectra (Nyquist plots) of unmodified $\mathrm{LiMn}_{2} \mathrm{O}_{4}$, TSD-LMO and TSC-LMO electrodes at 50\% DOD (a) during the first discharge and (b) after 30 cycles at $55^{\circ} \mathrm{C}$. The scatter points are the experimental data and the lines represent the simulation results using the equivalent circuit shown in the inset.

Table 1 | Fitting results for the impedance spectra in Fig. 9.

\begin{tabular}{|c|c|c|c|c|}
\hline Samples & $R_{\mathrm{SEI}}(\Omega)$ & $R_{\mathrm{ct}}(\Omega)$ & $\sigma\left(\Omega \mathrm{s}^{-1 / 2}\right)$ & $D_{L i}\left(m^{2} s^{-1}\right) \cdot A^{2}$ \\
\hline \multicolumn{5}{|l|}{ Before cycling } \\
\hline $\mathrm{LiMn}_{2} \mathrm{O}_{4}$ & 4.35 & 32.8 & 13.0 & $5.82 \times 10^{-12}$ \\
\hline TSD-LMO & 4.67 & 55.3 & 12.4 & $6.40 \times 10^{-12}$ \\
\hline TSC-LMO & 3.13 & 95.8 & 32.3 & $5.89 \times 10^{-12}$ \\
\hline \multicolumn{5}{|c|}{ After 30 cycles } \\
\hline $\mathrm{LiMn}_{2} \mathrm{O}_{4}$ & 11.9 & 65.4 & 28.4 & $1.22 \times 10^{-12}$ \\
\hline TSD-LMO & 4.86 & 54.7 & 13.6 & $5.32 \times 10^{-12}$ \\
\hline TSC-LMO & 3.44 & 96.0 & 36.9 & $4.52 \times 10^{-12}$ \\
\hline
\end{tabular}

is because the surface-doping layer maintains the spinel structure of the unmodified LMO for rapid lithium intercalation, while the surface-coating layer by ALD forms a partial physical barrier (Fig. 6f) that blocks lithium insertion.

Comparing Fig. 9a,b, a remarkable divergence in the impedance change between the unmodified and surface-modified LMO cathodes upon cycling can be observed. The $R_{\mathrm{ct}}$ of the unmodified $\mathrm{LiMn}_{2} \mathrm{O}_{4}$ electrode more than doubled after 30 cycles, from 4.35 to $11.9 \Omega$, and the $R_{\mathrm{SEI}}$ of the anode increased from 32.8 to $65.4 \Omega$. The increase in $R_{\mathrm{ct}}$ is caused by a structural change of the cathode surface because of $\mathrm{Mn}$ dissolution, and the increase in $R_{\mathrm{SEI}}$ results from the compositional change of the SEI at the anode due to $\mathrm{Mn}^{2+}$ deposition ${ }^{4,7}$. In contrast, the increase in impedance was negligible for the surface-modified LMO electrodes. Results from inductively coupled plasma-optical emission spectroscopy measurements showed that the concentration of $\mathrm{Mn}$ dissolved in the electrolyte decreased from 176 p.p.m. (unmodified LMO cell) to 135 p.p.m. (TSD-LMO cell) ${ }^{4}$ and 93 p.p.m. (TSC-LMO cell). Moreover, the concentration of Mn deposited on the anode was 792 p.p.m. for the unmodified LMO cell but only 250 p.p.m. (ref. 4) in the TSD-LMO cell and 263 p.p.m. in the TSC-LMO cell. These results clearly demonstrate that surface modification was effective in suppressing the Mn dissolution-migration-deposition process, leading to a negligible impedance rise for both the cathode and anode of the LMO-based cells. As a consequence, the cycling 
performance of the cells with surface-modified $\mathrm{LiMn}_{2} \mathrm{O}_{4}$ electrodes is improved significantly. In our earlier work, we have demonstrated the correlation between $\mathrm{Mn}$ deposition (and the consequent impendence rise at the anode) and capacity fading for the same system ${ }^{4}$, which is also consistent to the results presented in this study. In addition, the surface-doping could help to maintain the rate capability of the spinel because of the less increased impedance of the cathode. Finally, it should be pointed out that the Li diffusion path in the bulk of the spinel particles is barely affected by the surface modification as shown by fitting the low-frequency regions of the impedance spectra. These results are detailed in the Methods section.

\section{Discussion}

It should be noted that stoichiometric $\mathrm{LiMn}_{2} \mathrm{O}_{4}$ has been selected as the cathode material in the current study, since it is the model system for investigating the $\mathrm{Mn}$ dissolution phenomenon. However, stoichiometric $\mathrm{LiMn}_{2} \mathrm{O}_{4}$, especially with the nanoscale particle as in this work, is well known to have a severe $\mathrm{Mn}$ dissolution issue, which certainly leads to a very fast capacity decay at high temperature. With surface doping, the hightemperature performance of the stoichiometric $\mathrm{LiMn}_{2} \mathrm{O}_{4}-\mathrm{C}$ cell has been significantly improved, although it still shows capacity degradation upon cycling. More importantly, the main goal of the current study is to find a new alternative approach to the existing surface-coating method to improve the cell performance, as we have demonstrated in this study. In general, we are expecting that the surface-doping technique could also benefit other systems, including layered material such as $\mathrm{LiNi}_{x} \mathrm{Mn}_{y} \mathrm{Co}_{1-x-y} \mathrm{O}_{2}$, Li-rich materials $\left(x \mathrm{Li}_{2} \mathrm{MnO}_{3} \cdot(1-x) \mathrm{LiMO}_{2}\right.$ where $\mathrm{M}=\mathrm{Mn}, \mathrm{Ni}, \mathrm{Co}, \mathrm{Al}$, $\mathrm{Fe}$, and so on) and $5 \mathrm{~V}$ spinel $\left(\mathrm{LiMn}_{1.5} \mathrm{Ni}_{0.5} \mathrm{O}_{4}\right)$, since they also have the same $\mathrm{Mn}$ dissolution issues.

In summary, surface modification by ALD or sol-gel treatment has been shown to significantly improve the capacity and cycleability of $\mathrm{LiMn}_{2} \mathrm{O}_{4}$ cathodes at elevated temperature. In particular, the uniform surface-doping layer $\left(\mathrm{LiMn}_{2}{ }_{x} \mathrm{Ti}_{x} \mathrm{O}_{4}\right)$ achieved by sol-gel treatment is favourable for charge transfer since it retains the spinel structure, but it suppresses the dissolution and deposition of manganese by preventing the electrolyte erosion of $\mathrm{LiMn}_{2} \mathrm{O}_{4}$ particles. In addition, the surface-doping concept provides advantages over traditional surface-coating techniques because it maintains a continuous surface-to-bulk structure that minimizes phase segregation or separation at interfaces during cycling. These results suggest great opportunities to improve lithium-ion battery performance by optimization of the electrolyte-electrode interphase.

\section{Methods \\ Unmodified and modified $\mathrm{LiMn}_{2} \mathrm{O}_{4}$ synthesis and characterization.}

Stoichiometric $\mathrm{LiMn}_{2} \mathrm{O}_{4}$ particles were synthesized by heating a thoroughly ground mixture of $\mathrm{Li}_{2} \mathrm{CO}_{3}$ (Sigma-Aldrich, 99.0\%) and chemical $\mathrm{MnO}_{2}$ (Chemetal, 99.5\%; Mole ratio $=1.05: 4$ ) at $800^{\circ} \mathrm{C}$ for $12 \mathrm{~h}$ in air. For Ti-surface-doped $\mathrm{LiMn}_{2} \mathrm{O}_{4}$, tetrabutyl titanate (Sigma-Aldrich, 99\%) was used as the precursor. Tetrabutyl titanate was first dissolved in ethanol to make a $10 \%$ solution, and then the solution was slowly dropped into acetic acid solution (10\% acetic acid, 56\% ethanol and $34 \%$ water) with agitation to get the sol, which was further diluted to $5 \%$ by adding ethanol to prevent the aggregation of the colloidal. Then, the $\mathrm{LiMn}_{2} \mathrm{O}_{4}$ powders were added into the diluted sol, agitated for $20 \mathrm{~min}$, followed by drying at $80^{\circ} \mathrm{C}$ and calcination at $750^{\circ} \mathrm{C}$ for $4 \mathrm{~h}$.

The $\mathrm{TiO}_{2}-\mathrm{ALD}$ coating was performed in a continuous-flow stainless steel reactor described in detail elsewhere. About $300 \mathrm{mg}$ of the $\mathrm{LiMn}_{2} \mathrm{O}_{4}$ powders were carefully spread on a stainless steel tray and a stainless steel mesh cover was clamped over the tray to contain the powder while still providing access to the ALD precursor vapours. The $\mathrm{LiMn}_{2} \mathrm{O}_{4}$ powders were held in the reactor at $200^{\circ} \mathrm{C}$ under continuous flow of 300 s.c.c.m. ultrahigh-purity nitrogen-carrying gas at 1-torr pressure for $30 \mathrm{~min}$ to outgas and achieve thermal equilibrium. $\mathrm{The}^{\mathrm{TiO}} \mathrm{O}_{2}$ was deposited on the $\mathrm{LiMn}_{2} \mathrm{O}_{4}$ particles layer by layer for 10 cycles via alternating exposures to titanium isopropoxide (Sigma-Aldrich, 97\%) and deionized water at $200^{\circ} \mathrm{C}$ with time sequence $60-120-60-180 \mathrm{~s}$, corresponding to the precursor exposure time, $\mathrm{N}_{2}$ purge time, co-reactant exposure time and $\mathrm{N}_{2}$ purge time, respectively.

The unmodified and surface-modified $\mathrm{LiMn}_{2} \mathrm{O}_{4}$ particles were characterized by high-energy synchrotron XRD, which was carried out at the 11-ID-C beamline of the Advanced Photon Source, Argonne National Laboratory. The XRD patterns were collected in the transmission mode using a Perkin Elmer large area detector. The collected two-dimensional patterns were then integrated into conventional one-dimensional patterns (intensity versus $2 \theta$ ) for final data analysis using the Fit2d software. The XRD Rietveld refinement was carried out using the Fullprof Suite 2012

Samples were analysed by XPS using a Kratos Axis Ultra DLD surface analysis instrument. The base pressure of the analysis chamber during these experiments was $3 \times 10^{-10}$ torr, with operating pressures around $1 \times 10^{-9}$ torr. Spectra were collected with a monochromatic Al K $\alpha$ source $(1,486.7 \mathrm{eV})$ and a $300 \mu \times 700 \mu$ spot size. Photoelectron peak positions were shifted back towards their true values and their peak widths were minimized by flooding the samples with low-energy electrons and ions from the charge neutralizer system on the instrument. Peak position correction was further corrected by referencing the $\mathrm{C} 1$-s peak position of adventitious carbon for a sample $(284.8 \mathrm{eV}$, PHI Handbook of Photoelectron Spectroscopy) and shifting all other peaks in the spectrum accordingly. Fitting was carried out using the programme CasaXPS. Peaks were fit as asymmetric Gaussian/ Lorentzians, with $0-30 \%$ Lorentzian character. The full-width at half-maximum of all subpeaks was constrained to $0.7-2.0 \mathrm{eV}$, as dictated by instrumental parameters, lifetime broadening factors and broadening due to sample charging. With this native resolution set, peaks were added and the best fit, using a least-squares fitting routine, was obtained while adhering to the constraints mentioned above.

Scanning electron microscopy images were taken on Hitachi S5500 at $0.5 \mathrm{kV}$. In addition, the TEM images were taken by a field-emission transmission electron microscope (FEI Titan 80-300ST) with a spherical and chromatic aberration imaging corrector working at $80 \mathrm{kV}$. Spherical and chromatic aberration correction enables the microscope to attain resolution better than $0.1 \mathrm{~nm}$ (measured by Young's fringes) at $80 \mathrm{kV}$.

Electrochemistry tests. Cathode electrodes were prepared from mixture of $85 \%$ $\mathrm{LiMn}_{2} \mathrm{O}_{4}$ powders with or without surface modification, $10 \%$ carbon black and $5 \%$ polyvinylidene difluoride binder. 1-methyl-2-pyrrolidinone was used to make the mixture into a slurry, which was then casted on an aluminium foil using a $200-\mu \mathrm{m}$ doctor blade. After drying at $75^{\circ} \mathrm{C}$ in air for $4 \mathrm{~h}$ and another $12 \mathrm{~h}$ under vacuum, the laminates were compressed by a rolling press and then punched into $1.6-\mathrm{cm}^{2}$ disk electrodes. 2032 coin cells were assembled with electrodes Celgard 2325 separators and GenII electrolytes $\left(1.2 \mathrm{M} \mathrm{LiPF}_{6}\right.$ in 3:7 EC-EMC solution) in an Argon-filled glove box. Cycle performance of the spinel cathodes were compared by galvanostatical charge/discharge of the cells between 3.5 and $4.3 \mathrm{~V}$ at $55^{\circ} \mathrm{C}$ at $\mathrm{C} / 2$ (calculated by an anticipated capacity of $120 \mathrm{mAh} \mathrm{g}^{-1}$ for $\mathrm{LiMn}_{2} \mathrm{O}_{4}$ spinel). The capacity was calculated with pure $\mathrm{LiMn}_{2} \mathrm{O}_{4}$ as an active material. AC impedance spectroscopy of the two-electrode coin cells at 50\% DOD during the first discharge or after 30 cycles at $55^{\circ} \mathrm{C}$ were collected with an EG\&G 273A potentiostat and a Solartron SI1260 Frequency Response Analyzer using a 5-mV stimulating wave, with frequency ranging from $100 \mathrm{kHz}$ to $20 \mathrm{mHz}$.

Fitting of the impedance spectra. At low-frequency region, the real part of the impedance $\left(Z^{\prime}\right)$ is linear to the $-1 / 2$ power of the angular frequency $\left(\omega^{-1 / 2}\right)$, and the slope is call the Warburg coefficient $(\sigma)$. Using the thin-film model, by solving Fick's second law the Warburg coefficient can be also expressed as ${ }^{31}$ :

$$
\sigma=\frac{R T}{\sqrt{2 D_{\mathrm{Li}}} n^{2} F^{2} S C}
$$

where $R$ is the ideal gas constant, $T$ is the thermodynamic temperature, $F$ is the Faraday constant, $n$ is the valence, $D_{\mathrm{Li}}$ is the diffusion coefficient of the $\mathrm{Li}$ ions in the cathode, $C$ is the concentration of the $\mathrm{Li}^{+}$ions and $S$ denotes the contacting area between the active material particles and the electrolyte. For the unmodified $\mathrm{LiMn}_{2} \mathrm{O}_{4}$, TSD-LMO and TSC-LMO electrodes, the specific surface areas are similar because of their similar morphology (as can be seen in Fig. 2). Assuming the value of the specific area is $\mathrm{A} \mathrm{cm}^{2} \mathrm{~g}^{-1}$, the values of $D_{\mathrm{Li}}$ of the $\mathrm{LiMn}_{2} \mathrm{O}_{4}$ calculated from Equation (1) are also listed in Table 1. The diffusion coefficients of the Li ions in the unmodified and surface-modified LMO are similar, which indicates that the $\mathrm{Li}$ diffusion path in the bulk of the spinel particles is barely affected by the surface modification.

\section{References}

1. Armand, M. \& Tarascon, J. M. Building better batteries. Nature 451, 652-657 (2008).

2. Whittingham, M. S. Lithium batteries and cathode materials. Chem. Rev. 104, 4271-4301 (2004).

3. Guyomard, D. \& Tarascon, J. M. Li metal-free rechargeable $\mathrm{LiMn}_{2} \mathrm{O}_{4} /$ carbon cells - their understanding and optimization. J. Electrochem. Soc. 139, 937-948 (1992). 
4. Zhan, C. et al. $\mathrm{Mn}(\mathrm{II})$ deposition on anodes and its effects on capacity fade in spinel lithium manganate-carbon systems. Nat. Commun. 4, 2437 (2013).

5. Amatucci, G., Du Pasquier, A., Blyr, A., Zheng, T. \& Tarascon, J. M. The elevated temperature performance of the $\mathrm{LiMn}_{2} \mathrm{O}_{4} / \mathrm{C}$ system: failure and solutions. Electrochim. Acta 45, 255-271 (1999).

6. Amatucci, G. G. et al. Materials' effects on the elevated and room temperature performance of C/LiMn $\mathrm{O}_{4} \mathrm{Li}$-ion batteries. J. Power Sources 69, 11-25 (1997).

7. Amine, K. et al. Improved lithium manganese oxide spinel/graphite Li-ion cells for high-power applications. J. Power Sources 129, 14-19 (2004).

8. Blyr, A. et al. Self-discharge of $\mathrm{LiMn}_{2} \mathrm{O}_{4} / \mathrm{C} \mathrm{Li}$-ion cells in their discharged state. J. Electrochem. Soc. 145, 194-209 (1998).

9. Gummow, R. J., Dekock, A. \& Thackeray, M. M. Improved capacity retention in rechargeable $4 \mathrm{~V}$ lithium-lithium manganese oxide (spinel) cells. Solid State Ionics 69, 59-67 (1994).

10. Komaba, S. et al. Impact of 2-vinylpyridine as electrolyte additive on surface and electrochemistry of graphite for $\mathrm{C} / \mathrm{LiMn}_{2} \mathrm{O}_{4} \mathrm{Li}$-ion cells. J. Electrochem. Soc. 152, A937-A946 (2005).

11. Komaba, S., Kumagai, N. \& Kataoka, Y. Influence of manganese(II), cobalt(II), and nickel(II) additives in electrolyte on performance of graphite anode for lithium-ion batteries. Electrochim. Acta 47, 1229-1239 (2002).

12. Song, D., Ikuta, H., Uchida, T. \& Wakihara, M. The spinel phases $\mathrm{LiAl}_{\mathrm{y}} \mathrm{Mn}_{2-\mathrm{y}} \mathrm{O}_{4}(\mathrm{y}=0,1 / 12,1 / 9,1 / 6,1 / 3)$ and $\mathrm{Li}(\mathrm{Al}, \mathrm{M})_{1 / 6} \mathrm{Mn}_{11 / 6} \mathrm{O}_{4}(\mathrm{M}=\mathrm{Cr}$ $\mathrm{Co})$ as the cathode for rechargeable lithium batteries. Solid State Ionics 117, 151-156 (1999).

13. Lee, Y.-S., Kumada, N. \& Yoshio, M. Synthesis and characterization of lithium aluminum-doped spinel $\left(\mathrm{LiAl}_{\mathrm{x}} \mathrm{Mn}_{2-\mathrm{x}} \mathrm{O}_{4}\right)$ for lithium secondary battery. J. Power Sources 96, 376-384 (2001).

14. Shao-Horn, Y. \& Middaugh, R. L. Redox reactions of cobalt, aluminum and titanium substituted lithium manganese spinel compounds in lithium cells. Solid State Ionics 139, 13-25 (2001).

15. Yang, Y. et al. Single nanorod devices for battery diagnostics: a case study on $\mathrm{LiMn}_{2} \mathrm{O}_{4}$. Nano Lett. 9, 4109-4114 (2009).

16. Xiong, L., Xu, Y., Zhang, C., Zhang, Z. \& Li, J. Electrochemical properties of tetravalent Ti-doped spinel $\mathrm{LiMn}_{2} \mathrm{O}_{4}$. J. Solid State Electrochem. 15, 1263-1269 (2011).

17. Taniguchi, I., Song, D. \& Wakihara, M. Electrochemical properties of $\mathrm{LiM}_{1 / 6}$ $\mathrm{Mn}_{11 / 6} \mathrm{O}_{4}(\mathrm{M}=\mathrm{Mn}, \mathrm{Co}, \mathrm{Al}$ and $\mathrm{Ni})$ as cathode materials for $\mathrm{Li}$-ion batteries prepared by ultrasonic spray pyrolysis method. J. Power Sources 109, 333-339 (2002).

18. Markovsky, B. et al. Cycling and storage performance at elevated temperatures of $\mathrm{LiNi}_{0.5} \mathrm{Mn}_{1.5} \mathrm{O}_{4}$ positive electrodes for advanced $5 \mathrm{~V} \mathrm{Li}$-ion batteries. Electrochem. Commun. 6, 821-826 (2004).

19. Aurbach, D. et al. Studies of cycling behavior, ageing, and interfacial reactions of $\mathrm{LiNi}_{0.5} \mathrm{Mn}_{1.5} \mathrm{O}_{4}$ and carbon electrodes for lithium-ion $5 \mathrm{~V}$ cells. J. Power Sources 162, 780-789 (2006).

20. Thackeray, M. M. et al. $\mathrm{ZrO}_{2}$ - and $\mathrm{Li}_{2} \mathrm{ZrO}_{3}$-stabilized spinel and layered electrodes for lithium batteries. Electrochem. Commun. 5, 752-758 (2003).

21. Walz, K. A. et al. Elevated temperature cycling stability and electrochemical impedance of $\mathrm{LiMn}_{2} \mathrm{O}_{4}$ cathodes with nanoporous $\mathrm{ZrO}_{2}$ and $\mathrm{TiO}_{2}$ coatings. J. Power Sources 195, 4943-4951 (2010).

22. Cheng, H.-M. et al. Enhanced cycleabity in lithium ion batteries: resulting from atomic layer depostion of $\mathrm{Al}_{2} \mathrm{O}_{3}$ or $\mathrm{TiO}_{2}$ on $\mathrm{LiCoO}_{2}$ electrodes. J. Phys. Chem. C 116, 7629-7637 (2012).

23. Aarik, J., Aidla, A., Uustare, T., Ritala, M. \& Leskela, M. Titanium isopropoxide as a precursor for atomic layer deposition: characterization of titanium dioxide growth process. Appl. Surf. Sci. 161, 385-395 (2000).

24. Shin, Y. \& Manthiram, A. Influence of the lattice parameter difference between the two cubic phases formed in the $4 \mathrm{~V}$ region on the capacity fading of spinel manganese oxides. Chem. Mater. 15, 2954-2961 (2003).
25. Petrov, K. et al. Cation distribution and phase transformations in $\mathrm{LiMn}_{2-\mathrm{y}} \mathrm{Ti}_{\mathrm{y}} \mathrm{O}_{4}$ $(0.2<=\mathrm{y}<=1.5)$ solid solutions. Solid State Sci. 7, 277-286 (2005).

26. Krins, N. et al. $\mathrm{LiMn}_{2-\mathrm{x}} \mathrm{Ti}_{\mathrm{x}} \mathrm{O}_{4}$ spinel-type compounds $(\mathrm{x}<=1)$ : Structural, electrical and magnetic properties. Solid State Ionics 177, 1033-1040 (2006).

27. Avdeev, G., Manuel Amarilla, J., Maria Rojo, J., Petrov, K. \& Maria Rojas, R. Composition and structure of acid leached $\mathrm{LiMn}_{2-\mathrm{y}} \mathrm{Ti}_{\mathrm{y}} \mathrm{O}_{4}(0.2<=\mathrm{y}<=1.5)$ spinels. J. Solid State Chem. 182, 3226-3231 (2009).

28. Ohzuku, T., Kitagawa, M. \& Hirai, T. Electrochemistry of manganese-dioxide in lithium nonaqueous cell.3. X-ray diffractional study on the reduction of spinel-related manganese-dioxide. J. Electrochem. Soc. 137, 769-775 (1990).

29. Narayanan, S. R., Shen, D. H., Surampudi, S., Attia, A. I. \& Halpert, G. Electrochemical impedance spectroscopy of lithium-titanium disulfide rechargeable cells. J. Electrochem. Soc. 140, 1854-1861 (1993).

30. Barsoukov, E., Kim, J. H., Kim, J. H., Yoon, C. O. \& Lee, H. Kinetics of lithium intercalation into carbon anodes: in situ impedance investigation of thickness and potential dependence. Solid State Ionics 116, 249-261 (1999).

31. Takami, N., Satoh, A., Hara, M. \& Ohsaki, T. Structural and kinetic characterization of lithium intercalation into carbon anodes for secondary lithium batteries. J. Electrochem. Soc. 142, 371-379 (1995).

\section{Acknowledgements}

This work was primarily supported by the Center for Electrochemical Energy Science, an Energy Frontier Research Center funded by the US Department of Energy, Office of Science, Office of Basic Energy Sciences, including support for J.L., H.W., J.W.E., K.A. and A.J.K. (X-ray absorption studies). C.Z. and X.Q. were supported by the 973 Programme (2013CB934001, 2009CB220105) of China, Beijing Natural Science Foundation (2120001), National Natural Science Foundation of China (21273129) and 863 programme (2012DGF61480). Y.L. gratefully acknowledges the start-up support by the University of Alabama in Huntsville. Electron microscopy was carried out in the Electron Microscopy Center at Argonne, which is supported by the Office of Science under contract no. DE-AC02-06CH11357. Use of the Advanced Photon Source was supported by the US Department of Energy, Office of Science, Office of Basic Energy Sciences, under contract no. DE-AC02-06CH11357. Y.-K.S. acknowledges the financial support from the Human Resources Development of the Korea Institute of Energy Technology Evaluation and Planning (KETEP) grant funded by the Korea government Ministry of Knowledge Economy (No. 20124010203310) and by the National Research Foundation (NRF) of Korea grant funded by the Korea government (MEST; No. 2009-0092780).

\section{Author contributions}

J.L. designed the experiments; C.Z. synthesized the cathode materials; C.Z. and H.W performed and analysed the electrochemical experiments; A.J.K., J.L. and T.W. performed and analysed the X-ray absorption spectroscopy measurements; J.L. performed and analysed the XPS experiments; J.L., J.W. and D.J.M. performed and analysed the TEM data; Y.L. and J.W.E. performed the ALD experiment; X.Q and K.A. supervised the project; J.L., C.Z. Y.-K.S. and K.A. wrote the paper. All of the authors discussed the results and reviewed the manuscript.

\section{Additional information}

Competing financial interests: The authors declare no competing financial interests.

Reprints and permission information is available online at http://npg.nature.com/ reprintsandpermissions.

How to cite this article: Lu, J. et al. Effectively suppressing dissolution of manganese from spinel lithium manganate via a nanoscale surface-doping approach. Nat. Commun. 5:5693 doi: 10.1038/ncomms6693 (2014). 